\title{
MAIN ACRONYMS FOR INDICATING THE EFFECTIVENESS OF ADVERTISING COMMUNICATION OF MOBILE OPERATORS
}

\author{
L. Spasova*, Zh. Gundasheva \\ Department of Social Sciences and Business Language Training, Faculty of Economics, \\ Trakia University, Stara Zagora, Bulgaria
}

\begin{abstract}
This study focuses on advertising communication of mobile phone operators by indicating its effectiveness through the main acronyms for advertising influence.

The aim of the study is to define precisely the acronyms applied in the area of communications, while searching for psychological efficiency of advertizing and its indicators. In order to accomplish this aim we have set the following tasks:

- To study advertising communication of mobile phone companies

- To design a theoretical model of the acronyms, applied in communication

- To carry out T-tests for independent samples of demographic characteristics and emerging statistically significant factors

- $\quad$ To measure the psychological efficiency of advertisement and its indicators through a survey The following methods were used to accomplish the tasks: conducting two subsequent surveys with the same respondents regarding advertising perception and influence.
\end{abstract}

Key words: influence, persuasion, customer behaviour, satisfaction, advertisements.

\section{INTRODUCTION}

Advertisement is a creative strategy for mass communication that aims to transfer a message to a certain group of people, and to contribute to the stimulation of customers' demand for the products and services of a company that offers mobile, telecommunication and internet services. It is a "persuasive marketing communication"[1] through which goods and services are provided in order to be "implemented" into the minds of a large number of customers as such information that will facilitate the distribution of products and the accumulation of profit. This can be achieved with the help of professional communication strategies and tactics. As a persuasive element, it is a study subject of many sciences such as rhetoric, psychology, sociology, journalism, publicity, public relations. Its realization requires information

\footnotetext{
*Correspondence to: Lyubomira Venkova Spasova, Department of Social Sciences and Business Language Training, Faculty of Economics, Trakia University, Stara Zagora, Bulgaria, e-mail: liubomira1975@abv.bg
}

transfer from one source to a given recipient or a group of recipients.

\section{MAIN ACRONYMS FOR ASSESSING ADVERTISING INFLUENCE}

There are various acronyms in advertising theory according to which specific communication aims can be formulated, followed by advertising aims. Here we will list the following acronyms:

\section{AIDA - Attention, Interest, Desire, Action}

The first leading acronym for determining the level of advertising influence on the recipient's mind is the formula AIDA, developed back in 1896 by Elmo Levis with extended versions such as AIDMA, where "Motive" stands for the incentive to take action, and the AA in AIDMAA is for Action Again (repeated action) [6]. The cited formula has four aims which are created for an advertisement competing in an environment saturated with messages. The first main aim in advertising communication is to attract the attention of the target group - randomly or in a focused way, even relying on unusual measures. The second 
aim is to stimulate the interest in the advertising content. The third is to provoke customers' intent and will for taking action. Last, but not least - to guide those interests in a desired direction in order to provoke action.

\section{ACCA - Awareness, Comprehension,} Conviction, Action [10]

During the first stage there is always an element of attracting attention through various advertising media. Here the level of awareness of the individual customers is measured. The higher level of awareness which precedes the perception of the advertising argument raises the degree of persuasion and builds positive attitude to the perceived information. It also motivates the customer to take a first or repeated action, i.e. to make a purchase. This formula is typical for observing the behavior of the social environment based on the communication tasks of advertising. Here we do not consider the existence of a different image of the object of advertising, nor the fact that advertising has a delayed influence on the public in time.

DAGMAR - Defining advertising goals for measured advertising results [11]

DAGMAR is a typical hierarchical model of Russel Colly that includes four consecutive stages:

- $\quad$ Awareness - meaning and information about the product

- Comprehension - observations on the quality of goods

- Conviction - decision process for making a purchase

- $\quad$ Action - making a purchase or a deal

Three goals are reached according to this formula: instilling the information in the mind of the customer, image-making of the advertised products, and projecting uniqueness of the product into the customer's mind. These goals have led to the development of a new type of the DAGMAR formula, in which three advertising objectives are included: supporting the tendency to forget at a certain level, asserting the profiled image of the organizations and their trade marks, as well as creating an image for uniqueness of the products.

The 6-M methodology (MMMMMM) was developed as an addition and extension of DAGMAR to facilitate market analysis and goods. This methodology studies merchandise, market, motives, messages, media and measuring [9].
- $\quad$ Merchandise - strong and weak sides of the product and competition

channels, etc.

$$
\text { Market - customers, distribution }
$$

- $\quad$ Message - appellations of messages

- Measurement - choosing the most valid and reliable measurement procedures.

The application of some of the leading principles, as well as the use of different acronyms may be observed in the advertisements of Bulgarian mobile operators in respect to measuring its psychological effectiveness.

\section{PSYCHOLOGICAL EFFECT OF ADVERTISING ON MOBILE OPERATORS}

It has been found that psychological influence reaches five major areas of the human mind thought, attention, concepts, and feelings. It is measured in three stages: attracting attention, exciting or raising interest and provoking a decision for purchasing. The most important indicator for establishing the influence is memorization, i.e. perceiving and reproducing advertising appellation, memorizing part of the advertising story, reproducing the name of the company that indicates the company colour, etc. [2].

In many studies respondents have to indicate whether they can recall the advertisements of a certain organization, and also if they can remember any of the elements. A study on how memory reacts to this influence included semantic, episodic and procedural memory [3]. Semantic memory [5] is short-term, that is it "fleets away" easily. Researchers of this type of memory have shown that it dwindles when we sleep, also for short periods of time, when the information must be maintained in order for the customers to take immediate action.

Episodic memory [5] is a group of related memories, which are created by a definite multitude of experiences and emotions. Semantic and episodic memories create and shape one of the two big sections of memory the declarative section.

Procedural memory [5] belongs to the second section. It is long term and is related to methods, skills and procedures. The combination of different impact mechanisms on consumers' memory is applied also during advertising campaigns by mobile operators. 
The following hypothesis may be formulated on the basis of the presented theoretical material:

The composition of certain acronyms and their application while exercising the advertising influence of businesses may enforce the psychological effectiveness of advertising.

This hypothesis is about to be tested through a survey among youth at the ages of 18 to 25 who are using products and services of mobile operators in Bulgaria.

\section{SURVEY ON THE DEMOGRAPHIC CHARACTERISTICS OF YOUTH AT THE AGES OF 18 TO 25, EMERGING FACTORS AND BASE ACRONYMS}

In order to establish the effect of demographic data on advertisements of mobile operators, $\mathrm{T}$ tests for independent samples of individual demographic characteristics - gender and financial status - were made, and the relation with the emerging factors was explored. Statistically significant differences between the average values for the two genders for six of the factors extracted through analysis.

The T-test formula for independent samples is the following:

$$
t=\frac{\bar{x}_{1}-\bar{x}_{2}}{s_{p} \sqrt{\frac{1}{n_{1}}+\frac{1}{n_{2}}}}
$$

Where $s_{p}$ equals:

$$
s_{p}=\sqrt{\frac{\left(n_{1}-1\right) s_{1}^{2}+\left(n_{2}-1\right) s_{2}^{2}}{n_{1}+n_{2}-2}}
$$

The parameters in the formula correspond to:

$\overline{\mathrm{x}_{1}}-$ mean value of the first sample

$\overline{\mathrm{x}_{2}}-$ mean value of the second sample

$\mathrm{n}_{1}$ - size of the first sample (number of observations),

$\mathrm{n}_{2}$ - size of the second sample (number of observations),

$\mathrm{s}_{1-}$ standard deviation of the first sample,

$\mathrm{s}_{2}$ - standard deviation of the second sample,

$\mathrm{s}_{\mathrm{p}}$ - common standard deviation

\section{MAIN DEPENDENCES BETWEEN GENDER AND EMERGING FACTORS}

The results from the first significant T-test for independent samples show that gender as an independent variable differentiates significantly the responses of the participants for the factor "Interest for advertising". On this question the respondents have to indicate how they perceive advertisements from an operator of their choice. It is clear that the group of men has significantly higher mean values for this factor, namely $(\bar{x}=1.78)$ compared to the group of women, where ( $\bar{x}$ =1.66). The factor includes the following statements: "The ads are meaningless", "I have never understood them", "I don't trust them", and "They depress and limit me", where the higher values for the factor correspond to a higher degree of agreement with the statements. Thus, the male group in the present study demonstrates a more expressed inclination to reject advertisements as meaningless because they prefer the response items which are negative. This, therefore, confirms that men show greater mistrust for them. According to the presented acronyms, women have a higher incentive than men. The acronym AIDA - Attention, Interest, Desire, Action is applied when a purchase is made. $\mathrm{t}_{(298)}=-1.97 ; \mathrm{p}<0.05$

\section{Factor - Interest in advertising,} where $t=-1.973 p<0.05$, men -1.779 - mean values, women -1.658 - mean values

The results from the second significant T-test for independent samples show that gender has a significant effect on the responses of the participants for the factor "Socially valuable causes". This question alludes to those additional communications related to corporate social activity which would win the approval of mobile product and services users, and would be essential for stimulating customers' interest. In this test it is evident that the female group has significantly higher mean values for the factor $(\bar{x}=2.51)$ compared to the male group $(\bar{x}=2.36)$. In it the following statements are included - providing means for various social groups, holding sports events or actions for environmental protection, providing means for the treatment of animals, etc. Women are more likely to accept a larger range of these actions by giving them a higher evaluation. The results from the acronym ACCA Awareness, Comprehension, Conviction, Action [10] are indicated. The better awareness of the company can lead to using its products and services. $\mathrm{t}_{(298)}=2.458 ; \mathrm{p}<0.05$

\section{Factor - Socially valuable causes,} where $\mathrm{t}=2.458 \mathrm{p}<0.05$; men $-2.361-$ mean values; women -2.507 - mean values

According to the results from the third significant T-test for independent samples it has been found that gender has a significant effect on the 
responses of the participants for the factor "Effective components of advertising". This test shows that the female group has higher mean values for the factor $(\bar{x}=2.397)$ compared to the male group $(\overline{\mathrm{x}}=2.226)$. There are eight items for this factor: To provoke pleasure/ satisfaction; To have pleasant music; To show attractive actors; To make me watch it again; To create a feeling of freedom; To make me relax from my busy day; To be different from the rest; Not to irritate me with its content. They refer to the advertisements of the mobile operator chosen by the participants, where the high values for the factor correspond to a higher degree of agreement with the statements. From the analysis of the relevant values it becomes clear that there are not big differences between the two genders because their values are close. However, these results are distant from the value of $t=3.154 \mathrm{p}<0.01$. The acronym is ACCA - Awareness, Comprehension, Conviction, Action [10] $\mathrm{t}_{(298)}$ $=3.154 ; \mathrm{p}<0.01$.

\section{Factor - Effective components of advertising,}

where $\mathrm{t}=3.154 \mathrm{p}<0.01$; men $-2.226-$ mean values; women - 2.397 - mean values

To determine behavioral change in young respondents provoked by the influence of advertising, a T-test is applied by which the feeling after making a purchase is described. The results from this test show that gender as an independent variable also differentiates significantly the participants' responses for the factor "Satisfaction after making an online purchase". The male group has significantly lower mean values for this factor, namely ( $\mathrm{x}^{-}$ $=2.049$ ) compared to the female group where the values are $(\bar{x}=2.267)$. The factor includes the following items: I felt satisfied; I felt happy; Ifelt assured. The male group in these results demonstrates less satisfaction from the purchase compared to the female group. $\mathrm{t}_{(298)}=2.727$; $\mathrm{p}<0.01$

4. Factor - Satisfaction after an online purchase,

where $\mathrm{t}=2.727 \mathrm{p}<0.01$; men -2.049 ; women 2.267 .

In a completely opposite direction come the negative statements of the same question - 39, which also consolidate a factor with two items: I felt disappointed; I felt robbed. According to the results for the fifth significant $T$-test for independent samples it has been found that gender influences the responses for the factor "Disappointment after making an online purchase". This test shows that the female group has lower mean values for the factor $(\overline{\mathrm{x}}=1.578)$ compared to the male group with mean values ( $\mathrm{x}$ $=1.801$ ). This result reveals that men express a stronger degree of disappointment after making a purchase compared to women. Therefore, the influence of advertizing on them will be weaker. It is possible that the results may be related to the acronym DAGMAR - Defining Advertising Goals for Measured Advertising Results, in which there is a real purchase, i.e. action. $\mathrm{t}_{(298)}=$ 2.483; $\mathrm{p}<0.05$

5. Factor - Disappointment after an online purchase,

where $\mathrm{t}=-2.483 \mathrm{p}<0.05$, men -1.801 , women 1.578 .

The results from the first group of T-tests are presented in a table in order to trace the dependences between them. The purpose is to check whether the demographic or other characteristics of the emerging dependent variables have influenced their variation in the studied respondents (Table 1).

Table 1. T-tests for independent samples regarding gender

\begin{tabular}{|ll|l|l|l|}
\hline \multicolumn{2}{|l|}{ Factors } & $\begin{array}{l}\text { Degree of } \\
\text { freedom }\end{array}$ & $\mathrm{t}$ criterion & $\begin{array}{l}\text { Degree of } \\
\text { significance }\end{array}$ \\
\hline $1 . \quad$ & Interest in advertising & 298 & $\mathrm{t}=-1.973$ & $\mathrm{p}<0.05$ \\
\hline 2. & Socially valuable causes & 298 & $\mathrm{t}=2.458$ & $\mathrm{p}<0.05$ \\
\hline 3. & Effective components of advertising & 298 & $\mathrm{t}=3.154$ & $\mathrm{p}<0.01$ \\
\hline 4. & Satisfaction after an online purchase & 298 & $\mathrm{t}=2.727$ & $\mathrm{p}<0.01$ \\
\hline 5. & Disappointment after an online purchase & 298 & $\mathrm{t}=-2.483$ & $\mathrm{p}<0.05$ \\
\hline
\end{tabular}

\section{MAIN DEPENDENCES BETWEEN FINANCIAL STATUS AND FACTORS}

Together with the T-tests between gender and significant factors, other ones were also made regarding financial status declared by the respondents and the above-mentioned significant factors from the two surveys. T-tests for independent samples and single factor analyses with the mentioned demographic data were conducted to check their effect on the attitudes, thinking and behavior of target groups. These Ttests showed statistically significant results in the 
following characteristics: perception of advertising; advantages of the product, related to advertising; components for influence; motives for behavioral change; disappointment after making the purchase (Table 2).

Table 2: T-tests for independent samples for financial status

\begin{tabular}{|c|l|l|l|}
\hline Factors & $\begin{array}{l}\text { Degree of } \\
\text { freedom }\end{array}$ & t criterion & $\begin{array}{l}\text { Degree of } \\
\text { significance }\end{array}$ \\
\hline 1. Interest in advertising & 298 & $\mathrm{t}=3.908$ & $\mathrm{p}<0.01$ \\
\hline 2. Socially valuable causes & 298 & $\mathrm{t}=-2.915$ & $\mathrm{p}<0.01$ \\
\hline 3. Effective components of advertising & 298 & $\mathrm{t}=-3.385$ & $\mathrm{p}<0.01$ \\
\hline 4. Satisfaction after an online purchase & 298 & $\mathrm{t}=3.436$ & $\mathrm{p}<0.01$ \\
\hline 5. Disappointment after an online purchase & 298 & $\mathrm{t}=2.752$ & $\mathrm{p}<0.01$ \\
\hline
\end{tabular}

The results for the first significant T-test for independent samples for the financial state of the respondents and the first factor show that status as an independent variable differentiates significantly the responses of the participants for the factor "Interest in advertising". This result shows that the group with less financial means has considerably higher mean values for this factor, namely $(\overline{\mathrm{x}}=1.837)$ compared to those without financial constraints, where $(\overline{\mathrm{x}}=1.606)$. Therefore, youth with bigger financial capabilities do not define to a great extent the advertisements of the mobile operator of their choice as meaningless and can understand, as well as perceive them. This was proven by the item "I mistrust them", which was chosen by more financially constrained respondents and is a clear indicator for not perceiving the advertisements in question. The chosen acronym is AIDA -Attention, Interest, Desire, Action.

$\mathrm{t}_{(298)}=-1.97 ; \mathrm{p}<0.05$

1. Factor - Interest in advertising, where $\mathrm{t}=-1.97 ; \mathrm{p}<0.05$; Financially constrained -1.837 , Financially comfortable -1.606 .

According to the results from the second significant T-test for independent samples it has been found that financial status has a significant effect on the responses of the participants for the factor "Reasons for greater attention". This test shows that the group of financially comfortable has higher mean values for the factor $(\overline{\mathrm{x}}=2.349)$ compared to the group of financially constrained $(\bar{x}=2.187)$. Therefore, the elements of the factor have a greater impact on them when they watch advertisements of the mobile operator of their choice, i.e. those with better financial means are more likely to watch ads in order to make a purchase.

$\mathrm{t}_{(298)}=-2.915 ; \mathrm{p}<0.01$

2. Factor - Reasons for greater attention, where $\mathrm{t}=-2.915 \mathrm{p}<0.01$; Financially constrained -2.187 ; Financially comfortable -2.349 .
The results from the third significant T-test for independent samples show that the financial status determines significantly the responses of the participants for the factor: Advantages for the product related to advertising. The group of the financially comfortable has significantly higher mean values for this factor, namely $(\overline{\mathrm{x}}$ $=2.564$ ) compared to the other group (financially constrained), where $(\overline{\mathrm{x}}=2.712)$. The factor includes the following statements: I need it; It is convenient; Provides greater access to information; Provides faster access to the Internet; It makes me more mobile. Here the higher values correspond to a higher degree of agreement with the statements. In this case the financially comfortable group is more likely to take advantage of mobile phone and mobile internet under the influence of mobile company advertisements, compared to the financially constrained group. Thus, the results can be linked to the acronym DAGMAR - Defining Advertising Goals for Measured Advertising Results, in which there is a realized purchase.

3. Factor - Advantages of the product related to advertising, where $t=-3.385 \mathrm{p}<0.01$; financially constrained -2.564 ; financially comfortable -2.712 .

The results of the fourth significant $\mathrm{T}$-test for independent samples regarding the financial state of the respondents and the fifth factor show that status as an independent variable differentiates significantly the responses of the participants for the factor "Motives for behavioral change", where the financially constrained group has significantly higher mean values for this factor, namely $(\overline{\mathrm{x}}=2.059)$ compared to the financially comfortable group, where $(\overline{\mathrm{x}}=1.849)$. Therefore, youth with better financial resources are so often likely to change their mobile operator under the impact of its advertisement. This has been found in the items: My strong wish for change; My strong wish for using other services; My wish to use more mobile services. They were given more affirmative answers by the financially 
constrained, which is a clear sign that this group of respondents is more likely to change the agreed conditions of mobile services. These results correspond to the acronym 6-M (MMMMMM), where the motives for the relevant actions are sought.

$\mathrm{t}_{(298)}=3.436 ; \mathrm{p}<0.01$

4. Factor - Motives for behavioral change, where $\mathrm{t}=3.436 \mathrm{p}<0.01$; financially constrained- 2.059; financially comfortable 1.849 .

This significant result relates to the following $\mathrm{T}$ test for independent samples regarding the financial state of the respondents and the factor "Disappointment from an online purchase" which shows that financially constrained youth have significantly higher mean values for this factor, namely $(\overline{\mathrm{x}}=1.805)$ compared to the financially comfortable group, where $(\overline{\mathrm{x}}=1.561)$. The factor includes the following statements: $I$ felt disappointed; I felt robbed. Through them respondents indicate what their feelings are after an online purchase under the influence of a mobile operator advertisement. Therefore, the financially constrained are more disappointed, which will determine their subsequent behavior and attitude towards mobile companies.

. $\mathrm{t}_{(298)}=2.752 ; \mathrm{p}<0.01$

5. Factor - Disappointment from an online purchase, where $t=2.752 \mathrm{p}<0.01$

Financially constrained -1.805 ; financially comfortable - 1.561 .

\section{INFERENCES}

1) The study on the effectiveness of advertising is difficult to assess.

2) Applying various acronyms to measure the effect of advertisements facilitates the assessment of its effectiveness.

3) The behavioral change of young customers, as well as the assessment of their satisfaction or disappointment is due to the effectively developed advertising of the specific company.

4) These inferences partially prove the stated hypothesis because it is difficult to study all components of the presented acronyms.

These conclusions confirm the proposed hypothese to a certain extent.

\section{CONCLUSION}

The building and formulation of specific acronyms through which the influence of various advertisements of specific Bulgarian companies is assessed would facilitate the improvement of the psychological efficiency of advertising in general. The results obtained by the surveys show that men at the ages of 18 to 25 are less influenced by mobile operator advertisements in Bulgaria, and therefore they interact less with them. Women, on the other hand, rate these advertisements higher, and feel more satisfied by their purchases.

According to the results with respect to the demographic factor "financial status", financially constrained respondents define mobile operator advertisements as meaningless and futile, therefore, they are not inclined to interact with them, which shows they are less influenced by advertising. This statement is supported by the obtained result for a stronger disappointment by an online purchase made under the influence of advertising by financially constrained persons.

The conducted study focused on the psychological, age and existential aspects of youth being influenced by the advertising of mobile companies through specific acronyms.

\section{REFERENCES}

1. Cotlar, F., Marketing Management, Sofia: Classic style, Sofia, p. 34, 2007.

2. Krastev, S., Advertising-concepts, rules, examples, Sofia: SIELA, Sofia, p. 169, 2000.

3. Lakani, D., Subprag Conviction, Sofia: Anhira, Sofia, p.33, 2009.

4. Reeves, R. Reality in Advertising, Princeps, New York: Alfred A. Knopf., p.25, Varna, 1994.

5. Baddeley, D., Hitch, G.J., Working Memory. In The Psychology of Learning and Motivation (Bower, G.A., ed.), Academic Press, Oxford, UK: Oxford Univ. Press, pp. 47-89, 1974.

6. Colley, R., Defining Advertising Goals and Measuring Advertising Results, N.Y, p.287, 1995.

7. Goleman, D., Social Intelligence: the New Science of Human Relationships, N.Y.: Bantan, p.345, 2007.

8. Tulving, E., Elements of Episodic Memory. Oxford: Clarendon Press, p.67, 1983.

9. Wolfe, H. D., Measuring Advertising Effectiveness, New York; National Industrial Conference Board, 1961.

10. http://www.pmlive.com/intelligence/healthcar e_glossary_211509/Terms/d/defi.

11.http://www.investopedia.com/terms/d/dagmar .asp.

12.https://www.vbox7.com/play:3f7880d48a. 